\title{
ISPRS Archives
}

\section{Preface}

The content of this publication reflects on the developments in the field of $3 \mathrm{D}$ GeoInformation, as presented at the 11th 3D GeoInfo Conference 2016 (20-21 October, Athens, Greece). The conference is combined with the $5^{\text {th }} 3^{\mathrm{D}}$ Cadastres Workshop and the 3D Indoor Workshop, as "3D Athens 2016 Joint Conference". All papers included in this special issue, have been composed based on their peer reviewed extended abstracts that have been accepted for publication in ISPRS Archives by the Scientific Committee of the 11th 3DGeoInfo Conference. Therefore this publication comprises a selection of scientific contributions on the most recent developments in the fields of $3 \mathrm{D}$ GeoInformation Models and Systems, including among others, Big Data, Data Management, City Modeling, Environmental and Infrastructure Management. The conference topics are explicitly focusing on the latest achievements and future trends in this important field and are subject of intense and mature discussion between academics and practitioners during the 11th 3 DGeoInfo Conference.

As editors of this ISPRS special issue, we hope that decision makers, academics, engineers, computer scientists, land surveyors, urban planners, and students interested in the $3 \mathrm{D}$ GeoInformation area, will greatly benefit.

We would like to thank all the authors, the reviewers and especially the Organizing Committee for their valuable contributing to this publication.

Athens, October 2016

Efi Dimopoulou ${ }^{1}$ and Peter van Oosterom² ${ }^{2}$, The Editors

${ }^{1}$ School of Rural and Surveying Engineering, National Technical University of Athens, 9 Iroon Polytechneiou str, 15780 Zografou, Greece

${ }^{2}$ Delft University of Technology, Faculty of Architecture and the Built Environment, Department OTB, GIS

Technology Section, P.O. Box 5030, 2600 GA Delft, the Netherlands 